\title{
Professor J.S.M. Peiris - Fellow of the Royal Society, London
}

The election of Professor J. S. M. Peiris as a Fellow of the Royal Society of London in May 2006 is perhaps the (2) most important milestone in the history of the growth of science in Sri Lanka. There have been other significant steps in its developmental history - the formation of the Ceylon Association for the Advancement of Science in 1944; "In December 1943, on a suggestion made by D.H. Wadia, a former President of the Indian Science Congress, the Chemical Society of Ceylon spearheaded the formation of the Ceylon Association of Science, which in July 1944 was then constituted as the Ceylon Association for the Advancement of Science (CAAS). The ability of the Chemical Society of Ceylon to bring together scientists, engineers, medical personnel and social scientists under one banner was indeed a remarkable achievement." (de Silva M. A. T., Srl Lanka Journal of Social Sciences 1984, 7); the second major step was the establishment of the National Science Council in 1968. These two organizations have however been components in the machinery of science in Sri Lanka, a forum for the presentation and record of advances in science from local research and an advisory body to the government on matters pertaining to science in this country, respectively. Professor Peiris's election reflects the fact that a Lankan scientist, who had his formative experiences in science in his homeland, measures up to the acme of scientific stature, recognized world-wide, that this Fellowship signifies.

In a compilation of the list of Indian Fellows as at 2000 (Current Science, 2001, 80(6):721) there was only one medical scientist, Professor V. Ramalingaswamy, a medical scientist from the All India Institute of Medical Sciences, in New Delhi.

Since the significance of the Royal Society of London does not seem to be widely known among even the local scientists, leaving alone the lay persons, a brief statement about it is necessary to place Professor Peiris's achievement in correct perspective.

The Society was ".. founded in 1660 under the patronage of King Charles II and (is) still under Royal patronage, enjoying the present fellowship of queen Elizabeth and Prince Philip ... . The Royal Society is the oldest and most famous scientific society in the world" (Peter Medawar, 1984. The limits of science, Oxford, OUP). Fellows are however not appointed by the Queen or by the British government but by a lengthy process of election by current Fellows of the Society. Former Fellows have included physicist Robert Boyle (of Boyle's Law fame), and Sir Isaac Newton, while former Presidents included I J. Thompson (the discoverer of the electron) and Charles Darwin. Current Fellows include Stephen Hawking (A brief history of Time), Lucasian Professor of Mathematics, University of Cambridge, and Tim BernersLee (the inventor of the web).

The formation of the Society provided the essential ingredient, absent in 'science' in Asia, for the growth of science, as it was "....dedicated to free flow of information and encouraged communication..." between scientists, and provided an avenue for publication of the results of their scientific investigations in the Philosophical Transactions of the Royal Society begun in 1665, , that continues to this day.

In the citation for the election of Professor Peiris as a Fellow, was included the fact that he led the team that first identified the cause of SARS, the Severe Acute Respiratory Syndrome, and "has made immense contributions to our understanding of avian influenza and to antibody enhancement in Dengue and West Nile virus infection". Professor Peiris is the first Sri Lankan to have received that honour. His election as a Fellow of the Royal Society is a resounding rebuttal of the statement by an anonymous local writer of an article titled The NoNobel Syndrome (1998) about the bleak state of science in Lanka; "It is a fact that none of our scientists working here or abroad has not only (not) won a Nobel Prize but 
has not been elected to the Royal Society of London." This underscores an implication of a quote from a previous commentary on Professor Peiris's achievement (The Sunday Island, May 28, 2006): He has repeatedly said that his achievements in these years as a researcher in Sri Lanka, remain some of his proudest memories. It would be fair to say, however, that Peiris (and his colleagues) achieved what they achieved in Sri Lanka in spite of the system - not because of it. This should shake up and open the eyes of administrators of science and of senior scientists in this country, while his achievements could also provide a stimulus and a model to young Sri Lankan scientists who are at the beginning of their research careers.

Professor Peiris is now the Professor of Virology and Chair of the Department of Microbiology at the University of Hong Kong.

\section{Emeritus Professor S.N. Arseculeratne}

Department of Microbiology, Faculty of Medicine University of Peradeniya.

\section{Professor Tissa H. Illangasekare-Fellow of the American Association for the Advancement of Science}

Tissa H. Illangasekare, Ph.D., has been awarded the distinction of Fellow of the American Association for the Advancement of Science for 2006. Dr. Illangasekare holds the Colorado School of Mines AMAX Distinguished Chair of Environmental Science and Engineering and is a professor of civil engineering. Dr. Illangasekare is among 449 members elected by their peers to receive the award for their scientifically or socially distinguished efforts to advance science or its applications. Dr. Illangasekare, who also serves as director of the Center for Experimental Study of Subsurface Environmental Processes at Colorado School of Mines, was cited for his "distinguished contributions to improving fundamental understanding of flow and transport processes in soils and groundwater, including snow, through innovative laboratory, field and modeling studies."

Dr. Nigel Middleton, executive vice president for Academic Affairs, Colorado School of Mines, noted the honour is a "rare and prestigious award" within the scientific community.

"Dr. Illangasekare's experimental research in the remediation of subsurface environmental contaminants is making enormous contributions in the underlying sciences and associated engineering techniques," Middleton said. "The way in which he educates students in a context of cutting-edge research is truly exemplary, and his recognition by the AAAS is richly deserved. Colorado School of Mines is proud to have Dr. Illangasekare as a member of the faculty, and is proud of his election as a Fellow of the AAAS."

AAAS, founded in 1848, is the world's largest federation of scientists including more than 260 affiliated societies and academies of science serving 10 million people and publisher of the journal Science.

Colorado School of Mines, Colorado, USA

January 3, 2007 